\title{
Analysis of Losses in High Speed Slotless PM Synchronous Motor Integrated the Added Leakage Inductance
}

\author{
B.Q. Kou, H.C. Cao \\ Harbin Institute of Technology \\ Harbin, Heilongjiang, China
}

\author{
W.L. Li \\ Beijing Jiaotong University \\ Beijing, China
}

\begin{abstract}
- this paper researched the loss of high speed slotless permanent magnet synchronous motor (PMSM) with appended leakage inductance structure. This PMSM adopted novel stator structure to add the leakage inductance for solving the problem that high speed slotless PMSM inductance value is small. Compared with traditional motor, this motor adopted outer slottooth structure in stator iron; meanwhile it would add the iron loss. Therefore, this paper adopts the Bertotti separating iron model to calculate the iron loss of the stator with outer slot-tooth, then the iron loss in the yoke of stator was compared with the outer slot-tooth. The result proved that, the outer slot-tooth structure has less influence to stator iron loss. Secondly, the influence law between the appended leakage inductance and rotor eddy loss was analyzed. The paper analyzed rotor eddy loss under the condition of three kinds of winding that has different space distribution, and obtain the influence law between the winding space distribution and rotor eddy loss.
\end{abstract}

Keywords-PMSM; leakage inductance; influence law

\section{INTRODUCTION}

Due to advantages of high speed, high power density, small moment of inertia, etc., research of high-speed permanent magnet synchronous motor (HS-PMSM) has been more and more extensive application in fields of distributed power generation, flywheel energy storage, high speed centrifugal compressor, electric spindle and other. Now it has become the current research focus in the field of international electrotechnical (Paulides, Jewell \& Howe 2004, Wang 2006, Cho et al. 2011, Kong, Wang \& Xing 2012).

With the advantages of HS-PMSM, such as no cogging effect, high speed slotless permanent magnet synchronous motor (HSS-PMSM) could significantly reduce the torque ripple of the motor, so it is suitable for the occasion for low loss, low vibration and high accuracy. However, as less number of pole pairs and winding turns and large air gap than a slot motor, winding inductance value is usually very small and it would lead to produce a large number of current harmonics in the stator windings and a lot of eddy current losses in the rotor.

In response to these problems, the authors proposed a novel type of HSS-PMSM. The motor stator is composed of two parts of slotless stator core with outer slot and back around winding. It can produce additional leakage inductance use the outer slot to restrain stator current harmonic. The value of additional leakage inductance could adjust in large range by ad- justment of parameters of outer slot. Compared to traditional method that inductance is series connection in the external of motor in (Zwyssig, Round \& Kolar 2008, Koshio et al. 2009), the volume of motor itself is increased, but the integration of the system is greatly improved and the reliability of the system is increased.

The structure of outer tooth has greater diameter of novel core than the ordinary slotless motor, with increasing iron loss. But the greater value additional leakage inductance integrated in motor could significantly reduce the high-order harmonic current in the winding, and then reduce the eddy current loss in rotor. Therefore, a detailed calculation of iron loss and eddy current loss in the new structure motor is needed to compare.

\section{STRUCTURE OF NOVEL HSS-PMSM}

The stator structure of the integrated additional leakage inductance slotless motor is shown in Figure 1. The stator core is a slotless core with outside slot, the stator winding is a back wound winding and the inner side of the windings is fixed by sheet winding frame.

The wound back winding has been used as the motor's winding and the winding arrangement in a $1 / 4$ region is shown as Figure 2. After placing the first coil pieces $\left(A_{1}\right)$ in inner slot, the coil should be directly around into the corresponding outside $\operatorname{slot}\left(\mathrm{A}^{\prime}\right)$, and back from the stator end of the other side for continuing to place next coil side $A_{2}$ in the same pole group.

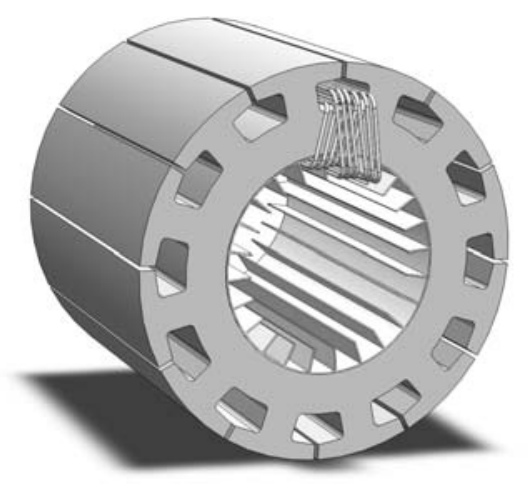

FIGURE I. STATOR OF THE INTEGRATED ADDITIONAL LEAKAGE INDUCTANCE SLOTLESS MOTOR. 


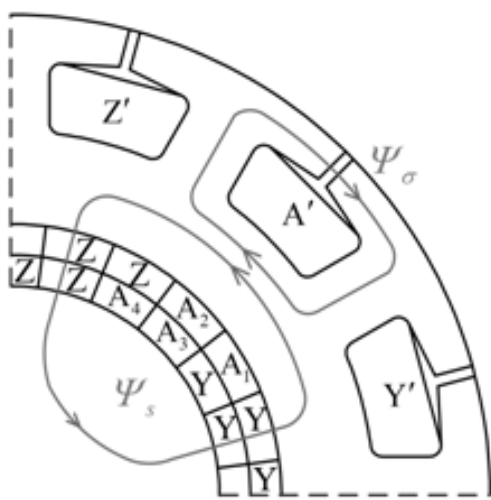

FIGURE II. WINDING ARRANGEMENT AND DISTRIBUTION OF THE FLUX.

When one phase winding is energized, the path of the winding flux is shown as Figure 2. The flux linkages $\Psi$ s surround the inside coil through the stator inner space, interacts with the magnetic field of the rotor to realization of electromechanical energy conversion. The flux linkages $\Psi_{\sigma}$ surround the outer coils only through the outside slot gap; do not enter inside of the stator. It can be equivalent as the leakage inductance series outside the motor to reduce the harmonic current. So, it can be called as additional leakage inductance.

A HSS-PMSM has been designed and the main parameters are shown in Table 1.

The winding self-inductance $\mathrm{L}_{\mathrm{s} 1}=0.152 \mathrm{mH}$ and the additional leakage inductance $\mathrm{L}_{\sigma}=0.152 \mathrm{mH}$, about 13 times of the winding self-inductance $\mathrm{L}_{\mathrm{s} 1}$.

\section{IRON LOSS ANALYSIS}

Due to the high frequency of magnetic field in the stator of the HS-PMSM, stator iron loss is great.

TABLE I. THE MAIN PARAMETERS OF PROTOTYPE MOTOR.

\begin{tabular}{|l|l|l|l|}
\hline Parameter & Value & Parameter & Value \\
\hline Phase & 3 & Air gap $(\mathrm{mm})$ & 1 \\
\hline Power $(\mathrm{kW})$ & 5 & Pole pairs & 2 \\
\hline Rated speed (rpm) & 15000 & Inside slots & 24 \\
\hline Rated voltage $(\mathrm{V})$ & 380 & Outside slots & 12 \\
\hline Core length $(\mathrm{mm})$ & 114 & Conductors per phase & 192 \\
\hline Inner diameter of stator $(\mathrm{mm})$ & 70 & Conductor per inside slot & 12 \\
\hline Outer diameter of stator $(\mathrm{mm})$ & 126 & Width of outside teeth $(\mathrm{mm})$ & 11 \\
\hline Inner diameter of PM $(\mathrm{mm})$ & 26 & Width of outside slot $(\mathrm{mm})$ & 1.4 \\
\hline Outer diameter of PM $(\mathrm{mm})$ & 50 & High of outside slot $(\mathrm{mm})$ & 5 \\
\hline Thickness of sleeve $(\mathrm{mm})$ & 1 & Width of outside slot $(\mathrm{mm})$ & 18 \\
\hline
\end{tabular}

In order to calculate the iron loss, the iron loss calculation model should be established. At present, calculation method based on Bertotti separation iron loss model is broad applications. This method considers the loss caused by the rotation of the magnetization and alternating magnetic in the core simultaneously. According to the reasons of loss generated, iron loss caused by arbitrary magnetic flux density waveform is decomposed into hysteresis loss, eddy current loss and additional loss.

\section{A. Iron Loss Calculation Model}

In the alternating magnetic field, the loss due to ferromagnetic materials is constantly repeated magnetization and magnetic domain constantly mutual friction is called hysteresis loss, its expression is:

$$
P_{h}=k_{h} B_{m}^{\alpha} f
$$

Where, $\mathrm{k}_{\mathrm{h}}$ is coefficient of hysteresis loss, $\mathrm{f}$ is frequency of magnetic field, $B_{m}$ is magnitude of the flux density, $\alpha$ is calculation parameters of hysteresis loss.

When the alternating magnetic field through the core, the eddy currents induced in the iron will cause eddy current losses, and its expression is:

$$
P_{c}=k_{c} B_{m}^{2} f^{2}
$$

Where, $k_{c}$ is coefficient of eddy current.

In addition, there is a part of loss neither belongs to hysteresis loss, also don't belong to eddy current loss, known as the additional loss, its expression is:

$$
P_{e}=k_{e} B_{m}^{1.5} f^{1.5}
$$

Where, $\mathrm{k}_{\mathrm{e}}$ is coefficient of additional loss.

Thus, according to the Bertotti separation iron loss model, iron loss power density per unit weight of iron core at a fixed magnetic field frequency can be expressed as follows:

$$
\mathrm{d} P_{F e}=k_{h} B_{m}^{\alpha} f+k_{c} B_{m}^{2} f^{2}+k_{e} B_{m}^{1.5} f^{1.5}
$$

\section{B. Analysis of Iron Loss in the Novel Type Slotless Stator}

A simulation model of the motor is built in Flux. And the core flux density distribution of the motor under no-load and load conditions can be obtained, as shown in Figure 3.

It can be seen, that the flux density in inner side stator yoke have little difference in no-load and load condition. This is because the smaller winding inductance of slotless motor makes armature reaction flux in load is small, less effect on the flux density of the inner stator yoke. And the magnetic flux density in stator outer teeth large changes in no-load and load conditions. This is due to the outside teeth is the main magnetic circuit of leakage flux produced by outside winding. At no-load, magnetic flux leakage produced by little current winding is also small, so flux density in the outer tooth of stator is small. At load, magnetic flux leakage produced by large current winding is also large, so flux density in the outer tooth of stator becomes larger. 


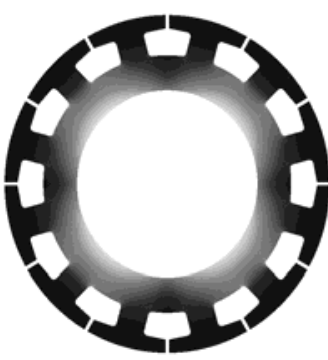

(a) No-load

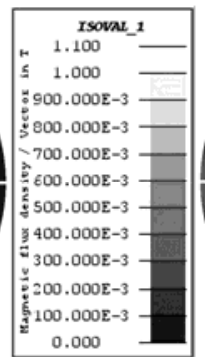

0.000

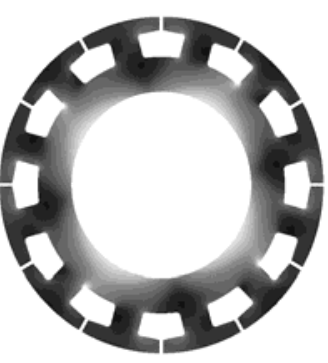

(b) Load
FIGURE III. IRON CORE FLUX DENSITY DISTRIBUTION.

In order to analyse the iron loss caused by the outside cogging structure of stator, the stator core area is divided into two parts, the inner ring part and the outer teeth part, as shown in Figure 4. Area of the inner ring is $2512 \mathrm{~mm} 2$, and the area of the outside tooth is $4164 \mathrm{~mm} 2$, about 1.66 times as much as the area of inside ring.

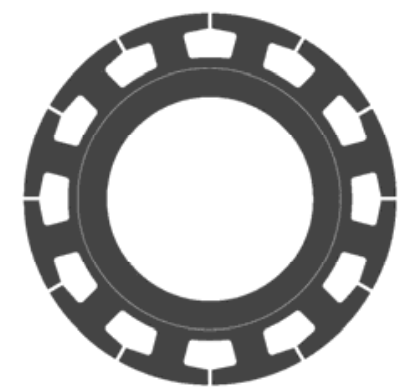

FIGURE IV. THE TWO SECTION OF THE STATOR CORE.

At different current frequencies, the two parts of the stator core loss is calculated by the analytical method and FEM simulation method, respectively. The results are shown in Figure 5. It can be seen, the iron loss of the outside tooth is very small, although its area is larger than the inner part. At noload, iron loss in the outside teeth is only about $18 \%$ of that in the inner ring; and at load, iron loss in outside teeth is about $40 \%$ of that in the inner ring. Iron loss Power density in outer teeth is far lower than that in the inner ring.

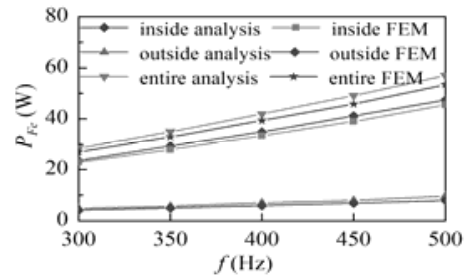

(a) No-load

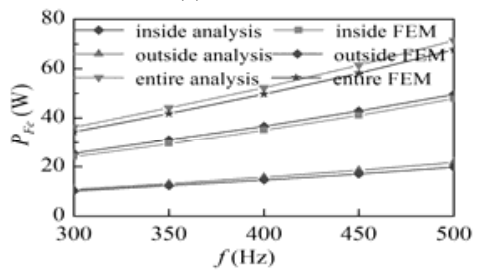

(b) Load

FIGURE V. IRON LOSS WITH FREQUENCY.
Therefore, in the actual design process, flux density in the outside tooth can be reduced as much as possible through rational design to reduce iron loss in outside teeth.

\section{EDDY CURRENT LOSS ANALYSIS}

Both permanent magnet and the rotor sleeve of HSSPMSM are conductors and will produce eddy current loss in the alternating magnetic field. In HS-PMSM, factors such as non-sinusoidal distribution winding magneto motive force, winding harmonic current induced by PWM chopper, et al, will produce a large number of harmonics in the air gap magnetic field. They will produce not to be neglected eddy current loss in the rotor. Meanwhile, most of the HS-PMSM is a sealing structure; condition of rotor cooling is poor. If the rotor's eddy current loss is too large, it will cause the temperature of permanent magnet increased significantly, and even cause demagnetization. In this paper, the relationship between the structure of stator and rotor eddy current loss is analysed.

\section{A. Influence on Eddy Current Loss by Additional Leakage Inductance}

In order to compare the HS-PMSM system without the additional leakage inductance and the HS-PMSM system with the additional leakage inductance, a motor that have the same inside winding parameters of the prototype but without the outside slot and additional leakage inductors is designed. Following, the motor with additional leakage inductance is named as motor $\mathrm{A}$, and the motor without additional leakage inductance is named as motor B. The system simulation of the two motors is studied using the Simulink. Modulation mode of the driver is SVPWM. The parameters of the two motors are shown in Table 2.

TABLE II. THE COIL PARAMETERS OF TWO MOTORS

\begin{tabular}{ccc}
\hline Prameters & Motor A & Motor B \\
\hline$R_{s}(\Omega)$ & 0.288 & 0.183 \\
$L_{d}(\mathrm{mH})$ & 2.282 & 0.248 \\
$L_{q}(\mathrm{mH})$ & 2.282 & 0.248 \\
$\Psi_{f}(\mathrm{~Wb})$ & 0.0907 & 0.0907 \\
$p$ & 2 & 2
\end{tabular}

Winding currents of the two motors are obtained by Simulink, as shown in Figure 6. It can be seen, that the harmonic current of the motor with additional leakage inductance is well suppressed.

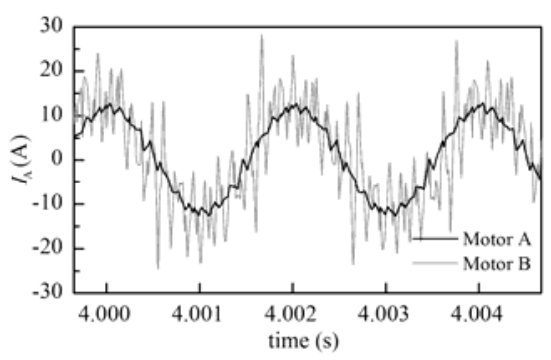

FIGURE VI. COMPARISON OF WINDING CURRENT OF TWO PROTOTYPES. 
FEM analysis of the two motors is carried out by using the current in Figure 6, the eddy current density of the rotors are obtained, as shown in Figure 7.

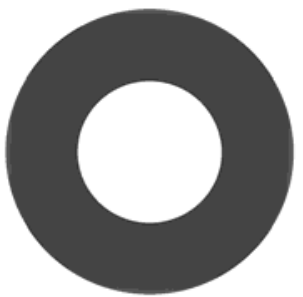

(a) Motor $\mathrm{A}$
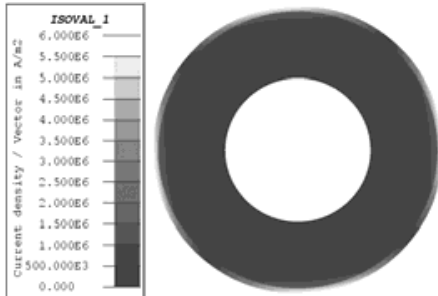

(b) Motor B
FIGURE VII. COMPARISON OF EDDY CURRENT DENSITY OF TWO PROTOTYPES

As less harmonic current in the motor A, eddy current density of the induction that generated in the rotor is relatively small, so the rotor eddy current loss is very small. The eddy current loss of the two motors was calculated, which in motor $\mathrm{A}$ is $2.35 \mathrm{~W}$, in motor B is $86.73 \mathrm{~W}$. Consequently, structure of additional leakage inductance can obviously reduce the rotor eddy current loss.

\section{B. Influence on Eddy Current Loss by Spatial Distribution of Winding}

In the slotless motor, the distribution of armature winding is uniform in space. In (Zhu et al. 2004), the spatial distribution of winding equivalent current sheet is directly decided by the spatial distribution of the stator winding. So, the spatial distribution of slotless motor stator winding has a direct relationship with rotor eddy current loss.

In order to analysis the relationship between the spatial distribution of winding and the eddy current loss, three kinds of armature winding are discussed in the following text. Figure 8 shows the diagram of space structure of the three kinds of windings. Among them, Figure $8 \mathrm{a}$ is a 12 slot single layer winding. This structure is relatively simple, but the harmonic of back EMF and harmonic of spatial distribution is large. Figure $8 \mathrm{~b}$ is a 24 slot double layer short pitch winding adopted in the prototype, which is used in motor frequently. And in this paper, a newly quasi-sinusoidal winding based on the 24 slot double layers winding is proposed, as shown in Figure 8c. The distribution of winding under each pole phase group is similar to the sine along with the changes of space angles.

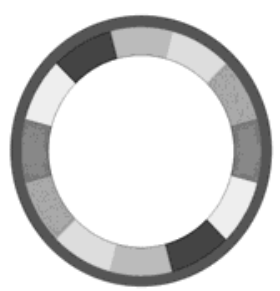

(a) 12 slot

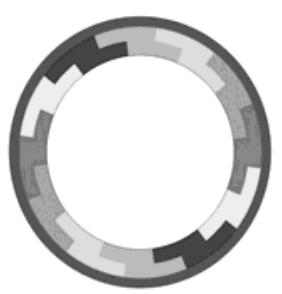

(b) 24 slot

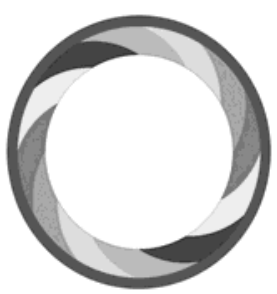

(c) quasi-sinusoidal
FIGURE VIII. SPATIAL DISTRIBUTION OF THREE KINDS OF WINDINGS.

At time $t=0$, the equivalent current sheet waveform of the three kinds of winding are shown in Figure 9. It can be seen, the equivalent current sheet waveform of the 12 slot single layer windings is very rough because its winding distribution is more concentrated. The equivalent current sheet waveform of 24 slot double layers winding has greatly improved. And the equivalent current sheet waveform of quasi sinusoidal winding is very close to the sine wave.

The total harmonic distortion (THD) is used to evaluate the properties of the three kinds of winding structure, the contrast results are shown in Table 3. It can be seen from Table 3, the difference of fundamental amplitude between the three kinds of winding is very small, but the difference of THD is very.
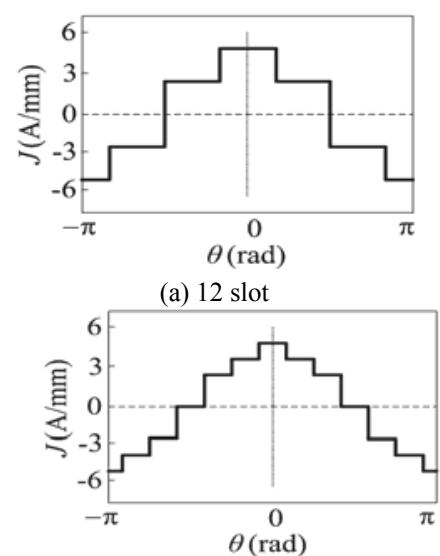

(b) 24 slot

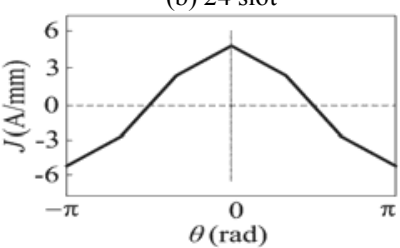

(c) quasi-sinusoidal

FIGURE IX. SPACE DISTRIBUTION OF WINDING'S EQUIVALENT CURRENT SHEET.

Obvious. Among them, the THD of the quasi sinusoidal winding is minimum, only $4.67 \%$. Therefore, from the perspective of space harmonic, the quasi sinusoidal winding which has fundamental amplitude close to the full pitch winding and also has a very small THD, it's a very excellent winding structure.

TABLE III. COMPARISON OF THREE KIND OF COIL STRUCTURE.

\begin{tabular}{|c|c|c|c|}
\hline \multirow{3}{*}{$\begin{array}{l}\text { Fundamental amplitude } 5 \\
\qquad(\mathrm{~A} / \mathrm{mm})\end{array}$} & \multirow{2}{*}{\multicolumn{2}{|c|}{$\begin{array}{cc}12 \text { slot } \quad 24 \text { slo } \\
290 & 5.135\end{array}$}} & \multirow{2}{*}{$\begin{array}{l}\text { Quasi-sinusoidal } \\
5.076\end{array}$} \\
\hline & & & \\
\hline & 31.35 & 16.78 & 4.67 \\
\hline
\end{tabular}

Figure 10 is the distribution of eddy current density in sleeve and permanent magnet of the rotor of the motors with three kinds of winding with the same current. From the sleeve region in Figure 10, it can be seen, that the eddy current density produced by 12 slot winding is highest, and the eddy current density produced by quasi sinusoidal winding is the lowest. 


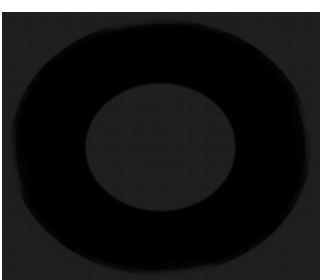

(a) 12 slot

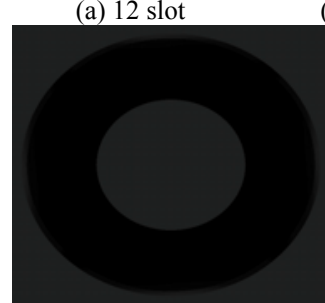

(c) quasi-sinusoidal

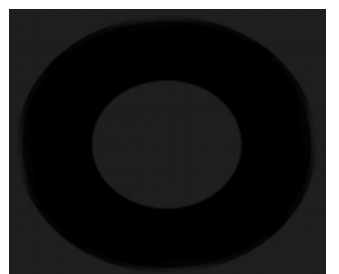

(b) 24 slot

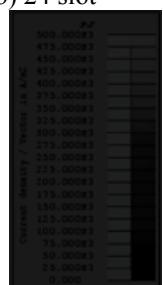

(d)legend
FIGURE X. DISTRIBUTION OF EDDY CURRENT DENSITY IN ROTOR.

The rotor eddy current loss of motors with three kinds of winding is shown in Table 4. It can be seen, that the rotor eddy current loss of 12 slot winding is maximum, and the eddy current loss of quasi sinusoidal winding is minimum. Moreover, substantial of eddy current loss in sleeve is more than in the permanent magnet.

TABLE IV. EDDY CURRENT LOSS OF THREE KIND OF WINDING.

\begin{tabular}{lccc}
\hline Eddy current loss 12 slot & \multicolumn{2}{c}{24 slot } & \multicolumn{2}{c}{ Quasi-sinusoidal } \\
In sleeve (W) & 1.60 & 1.49 & 1.45 \\
In PM (W) & 0.93 & 0.86 & 0.84 \\
Total (W) & 2.53 & 2.35 & 2.29 \\
\hline
\end{tabular}

Therefore, during the design of the motor, to minimize the rotor eddy current losses, we should try to make the spatial distribution of winding under each pole phase group nearly sinusoidal.

\section{CONCLUSION}

(1) This paper introduces a new kind of HSS-PMSM. This motor integrates additional leakage inductance inside, that can reduce the winding current harmonics and meanwhile will increase the area of the stator core.

(2) Iron loss of motor which is analyzed by Bertotti separation iron loss model is compared with the simulation results. The compare result describes that additional leakage structure leads that the stator core area increased by $160 \%$, but the stator iron loss increase only $19.79 \mathrm{~W}$, not to the iron loss of inner part $40 \%$.

(3) The rotor eddy current loss with or without appended inductance are analyzed by Simulink tool. The Simulink result could be proved that additional leakage inductance structure could restrain the winding current harmonics well, and can reduce the eddy current loss more than $95 \%$.

(4) Three kinds of winding space distribution structure are analyzed and compared. The results show that, with the winding distribution close to the sinusoidal distribution in space, eddy current losses are also reduced.

\section{ACKNOWLEDGEMENT}

This paper was supported by International Cooperation (2013DFR60510), Ministry of Science and Technology of China. Their powerful supports are grateful.

\section{REFERENCES}

[1] Cho, H.W., Ko, K.J., Choi, J.Y. \& et al. 2011. Rotor natural frequency in high-speed permanent magnet synchronous motor for turbocompressor application. IEEE Transactions on Magnetics 47(10): 42584261.

[2] Kong, X.G., Wang, F.X. \& Xing, J.Q. 2012. Losses calculation and temperature field analysis of high speed permanent magnet machines. Transaction of China Electrotechnical Society 27(9): 166-173.

[3] Koshio, N., Kubota, K., Miki, I. \& et al. 2009. Improvement of current waveforms of position sensor-less vector controlled permanent magnet synchronous motor at high frequency region. International Conference on Electrical Machines and Systems, Tokyo, Japan: 1-5.

[4] Paulides, J.J.H., Jewell, G.W. \& Howe, D. 2004. An evaluation of alternative stator lamination materials for a high-speed, $1.5 \mathrm{MW}$, permanentmagnet generator. IEEE Transactions on Magnetics, 40(4): 2041-2043.

[5] Wang, F.X. 2006. Study on design feature and related technology of high speed electrical machines. Journal of Shenyang University of Technology 28(3): 258-264.

[6] Zhu, Z.Q., Ng, K., Schofield, N. \& Howe, D. 2004. Improved analytical modeling of rotor eddy current loss in brushless machines equipped with surface-mounted permanent magnets. IEE Proc. Electric Power Applications, 151(6): 641-650.

[7] Zwyssig, C., Round, S. \& Kolar, J. 2008. An ultrahigh-speed, low power electrical drive system. IEEE Transactions on Industrial Electronics, 55(2): $577-585$. 